\title{
The Effect of Ginger and Thyme on Some Biochemical Parameters in Diabetic Rats
}

\author{
Emily T. Hanna ${ }^{1}$, Walaa I. M. Aniess ${ }^{2}$, Ayman F. Khalil ${ }^{2}$, Eveleen S. Abdalla ${ }^{2}$, \\ Elsayed A. Hassanin ${ }^{1}$, Ereny W. Nagib ${ }^{2}$ \\ ${ }^{I}$ (Nutrition Biochemistry and Metabolism Dept., National Nutrition Institute, Cairo, Egypt.) \\ ${ }_{2}^{2}$ (Home Economics Department, Faculty of Specific Education/Ain Shams University, Cairo, Egypt)
}

\begin{abstract}
Diabetes mellitus (DM) is one of the chronic metabolic diseases. The present study was carried out to investigate the effect of ginger and thyme on some biochemical parameters in diabetic rats. Fifty-six male albino rats were divided into eight groups; 7 rats each. Negative control, positive control and other six groups were fed standard diet with $0.5 \%, 1 \%$ and $5 \%$ ginger and $2 \%, 5 \%$ and $10 \%$ thyme respectively for six weeks. Plasma samples were separated for different biochemical analysis. Livers were kept in $10 \%$ formalin for histological study. Hemoglobin was increased in 5\% ginger and 10\% thyme while total protein was increased only in 5\% ginger compared with diabetic group. Rats fed 5\% ginger and 10\% thyme showed decrease in glucose level, total cholesterol, triglycerides, $L D L-C, V L D L-C$, uric acid, creatinin and urea nitrogen and increase in HDL-C compared with diabetic control. Liver functions were improved in diabetic groups when they fed (5\%) ginger and (10\%) thyme. It could be seen that there was statistically more significant improvement in (5\%) ginger than (10\%) thyme in glucose and HDL-C.
\end{abstract}

Keywords: Diabetes, Ginger, Glucose, Histology, Thyme

\section{Introduction}

International Diabetes Federation (IDF) estimated that there were 34.6 million people with diabetes mellitus (DM) in the Middle East and North Africa, a number that will almost double to 67.9million by 2035 if concerted action is not taken to tackle the risk factors fuelling the epidemic of diabetes throughout the Region [1]. The global prevalence of DM in the year 2010 among adults has been estimated to be $6.4 \%$. It is estimated that by the year 2030, Egypt will have at least 8.6 million adults with diabetes [2].

DM is known to impair many physiological functions. Some reports claim that medicinal plants can reduce these alterations caused by DM.

Ginger (Zingiber Officinale Roscoe, Zingiberaceae), is one of the most widely used herbs in Asian countries and now in Egypt as a commercial commodity. Ginger ethanolic extract possesses analgesic, antiinflammatory and hypoglycemic properties in animal study [3].

Researches showed that ginger significantly lowered lipid peroxidation by maintaining activities for the antioxidant enzymes; Super oxide dismutase, catalase and glutathione peroxidase in rats [4]. [5] revealed a protective role of ginger on the diabetic brain via reducing oxidative stress, apoptosis, and inflammation.

Thyme (Thymus vulgaris L.), is an aromatic plant of the Mediterranean flora commonly used as spices and for medicinal purposes. Like other various species, thyme is traditionally used for its antiseptic, antispasmodic, and antitussive effects. Furthermore, thyme possesses antimicrobial, antifungal, antioxidative, and antiviral properties [6].

The essential oil derived from thyme is a mixture of monoterpenes and one of the main compounds of this oil is a natural terpenoid thymol [7]. Thymol exhibits multiple biological activities including antioxidant [8], and free radical scavenging properties [9]. Thymus vulgaris aqueous-methanol extract have remarkable potential to counteract DM-caused alterations, probably through their antioxidant and free radical-defusing effects [10].

\section{Aim Of The Study}

The present study was carried out to investigate the effect of each of ginger and thyme on some biochemical parameters in diabetic rats.

\section{$1 \quad$ Materials:}

\section{Materials And Methods}

Fifty-six male albino rats weighting $(160+10 \mathrm{~g})$ of Sprague Dawley Strain were obtained from Vaccine and Immunity Organization, Helwan farm, Cairo, Egypt. Powdered dried Chinese ginger root and dried Libyans thyme were purchased from Agricultural Seed, Spices and Medicinal Plants Co. (Harras), Cairo, Egypt. 


\section{Methods:}

\subsection{Experimental diet:}

Standard diet was prepared per 100 gm from the following ingredients: sunflower oil $10 \%$, salt mixture $4 \%$ [11], vitamin mixtures 1\% [12], DL methionine $0.3 \%$, cellulose $5 \%$ and cholin chloride $0.2 \%$. Casein was added to represent $14 \%$ protein according to [13]. The protein was added at the expense of starch.

\subsection{Experimental design:}

Fifty six male albino rats of Sprague- Dawley strain weighting $(160 \pm 10 \mathrm{~g})$ were divided into eight groups; 7 rats each. Feed and water were provided ad libitum. The first group ( 7 rats) was fed standard diet only as negative control. The other seven groups ( 49 rats) were rendered diabetic by subcutaneous injection of freshly prepared alloxan monohydrate in saline $150 \mathrm{mg} / \mathrm{kg}$ body weight according to [14]. Immediately after injection, animals were received 5\% glucose solution over night to overcome drug-induced hypoglycemia [15]. After five days, blood glucose was analyzed by a drop of blood obtained from tail vein and subjected to a strip of hemogluco test to ensure occurrence of diabetes in rats. Rats with fasting blood sugar $>126 \mathrm{mg} / \mathrm{dl}$ were considered diabetic according to [16]. Then one group (7 rats) was fed on standard diet as a positive control (Diabetic control) for 6 weeks. The other six groups were fed standard diet with $0.5 \%, 1 \%$ and $5 \%$ ginger and $2 \%, 5 \%$ and $10 \%$ thyme respectively for six weeks.

At the end of the experimental period, all rats were sacrificed under ether anesthesia after overnight fasting. Blood samples were taken from the hepatic portal vein in heparinized tubes. Blood was centrifuged at 3500 r.p.m. for 15 min., plasma samples were separated and stored frozen at $-20^{\circ} \mathrm{c}$ for different biochemical analysis.

\subsection{Biochemical analysis:}

Blood hemoglobin and Blood total protein were determined according to [17 and 18] respectively. Blood glucose was determined using hemogluco test. Plasma triglycerides (TG), total cholesterol (TC) and highdensity lipoprotein-cholesterol (HDL-C) were determined according to the methods of [19, 20 and 21] respectively. Estimation of serum low-density lipoprotein cholesterol LDL-cholesterol was done according to the [22] equation. Plasma uric acid, Urea Nitrogen and Creatinine were determined according to the methods described by [23, 24 and 25] respectively. Aspartate amino transferases (AST) and Alanine amino transferases (ALT) were measured according to the method described by [26].

The results were analyzed statistically using computer statistical package software SPSS windows according to the method described by [27].

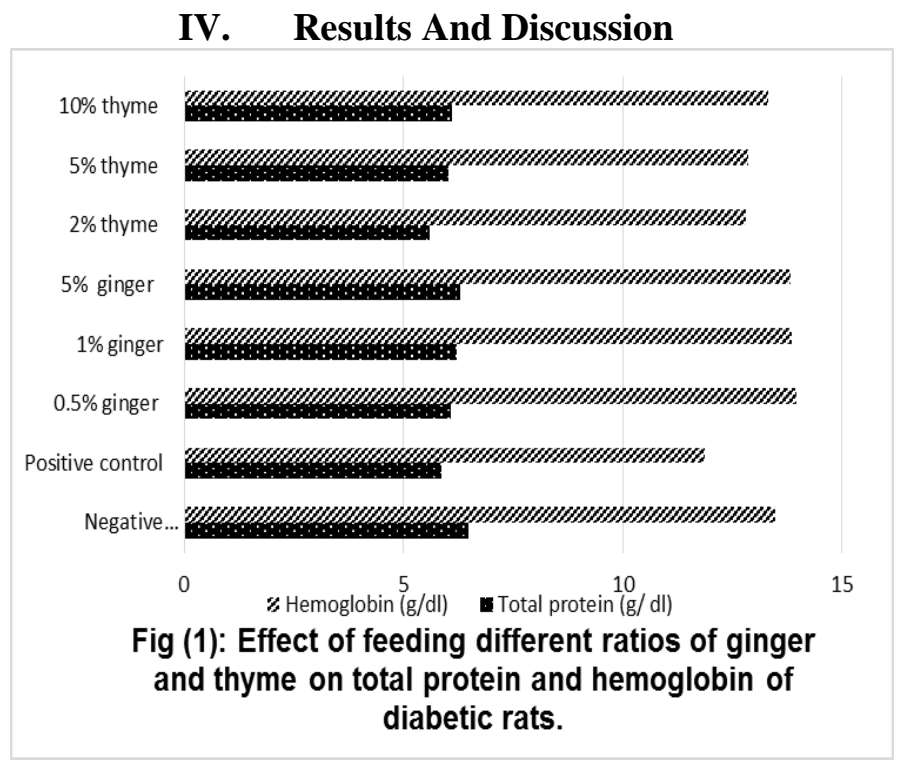

Results presented in "Fig." (1) revealed that the plasma total protein was significantly lower in positive control and in rats fed ( $2 \%)$ thyme group compared with negative control. However, there was a highly significant increase in (1\% and 5\%) ginger groups compared with positive control. These results were in agreement with that obtained by [28, 29 and 30]. The blood hemoglobin was significantly lower in positive control than negative control group. However, there was a significant increase in $(0.5 \%, 1 \%$ and $5 \%)$ ginger groups and in rats fed (10\%) thyme group compared with positive control groups. 


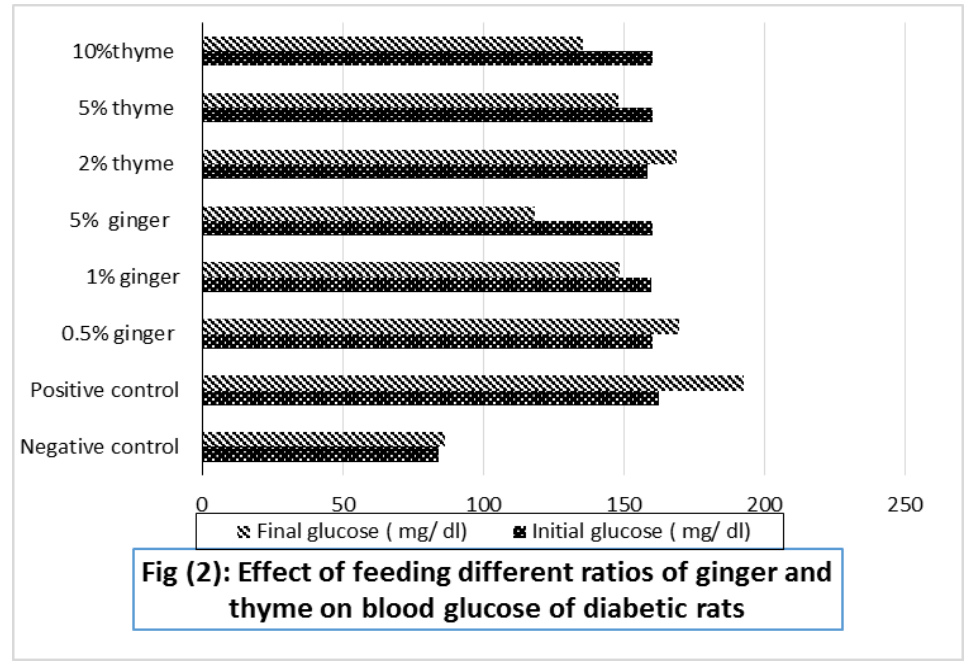

Data presented in "Fig." (2) clarified that injection with alloxan caused highly significant increase in blood glucose in positive control, $0.5 \%, 1 \%$ and $5 \%$ ginger groups and $2 \%, 5 \%$ and $10 \%$ thyme groups as compared with negative control. Rats fed with $1 \%$ and $5 \%$ ginger groups and 5 and $10 \%$ thyme showed significant reduction in glucose as compared with positive control. These results were in agreement with [31, 32 and 33]. [34] concluded that dietary ginger has hypoglycaemic effect, enhances insulin synthesis in male rats and has high antioxidant activity.

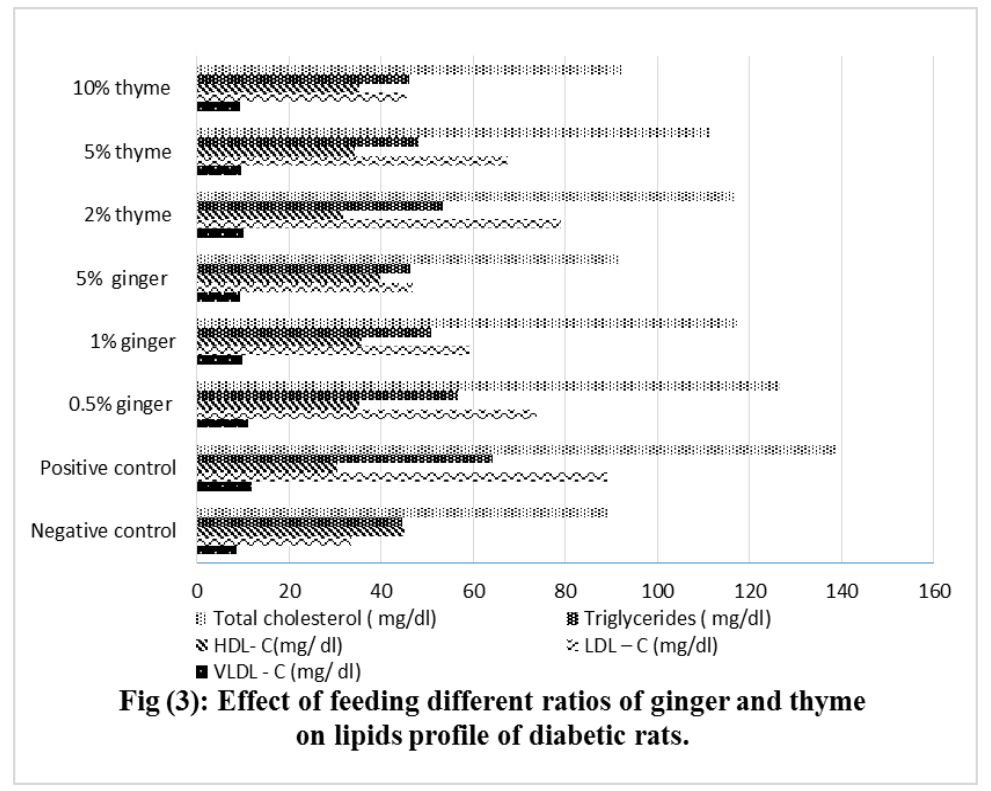

Results presented in "Fig." (3) revealed that injection with alloxan significantly raised plasma total cholesterol and triglycerides in positive control, $2 \%$ and 5\% thyme group as compared with negative control. Plasma total cholesterol and triglycerides were significantly decreased in $(0.5 \%, 1 \%$ and $5 \%)$ ginger group and $2 \%, 5 \%$ and $10 \%$ thyme groups rats compared with positive control group. These results were in agreement with [35, 36 and 37]. [38] investigated that TG accumulation in tissues causes insulin resistance and induces impairment of pancreatic beta-cell function. A reduction in TG led to reductions in body weight and intraabdominal fat weight, decreases in plasma TG, insulin and glucose levels and decrease in the TG secretion, decreases in the TG content in the liver, pancreas and muscles, improvement of the glucose infusion rate (GIR) and an improvement of pancreatic beta-cell function. HDL-C of positive control, $0.5 \%$ and $1 \%$ ginger and $2 \%$ and 5\% thyme fed rats groups was significantly decreased as compared with negative control. It was observed that plasma HDL-C significantly increased in (5\%) ginger and 10\% thyme groups as compared with positive control. These results were in agreement with [39, 40 and 31]. Plasma LDL- C was significantly increased in positive control, $0.5 \%, 1.0 \%$ and $5 \%$ ginger, $2 \%$ and $5 \%$ thyme groups and VLDL - C was significantly increased in diabetic and $0.5 \%$ and $1 \%$ ginger groups and $2 \%$ and $5 \%$ thyme groups as compared with negative 
control. However, it was observed that plasma LDL- C and VLDL - C were significantly decreased in $1 \%$ and $5 \%$ ginger and $2 \%, 5 \%$ and $10 \%$ thyme fed groups as compared with positive control. The results were in the line with [41 and 42]. [10] found that the lipid profile was ameliorated especially by supplementations of Thymus vulgaris on diabetic rats.

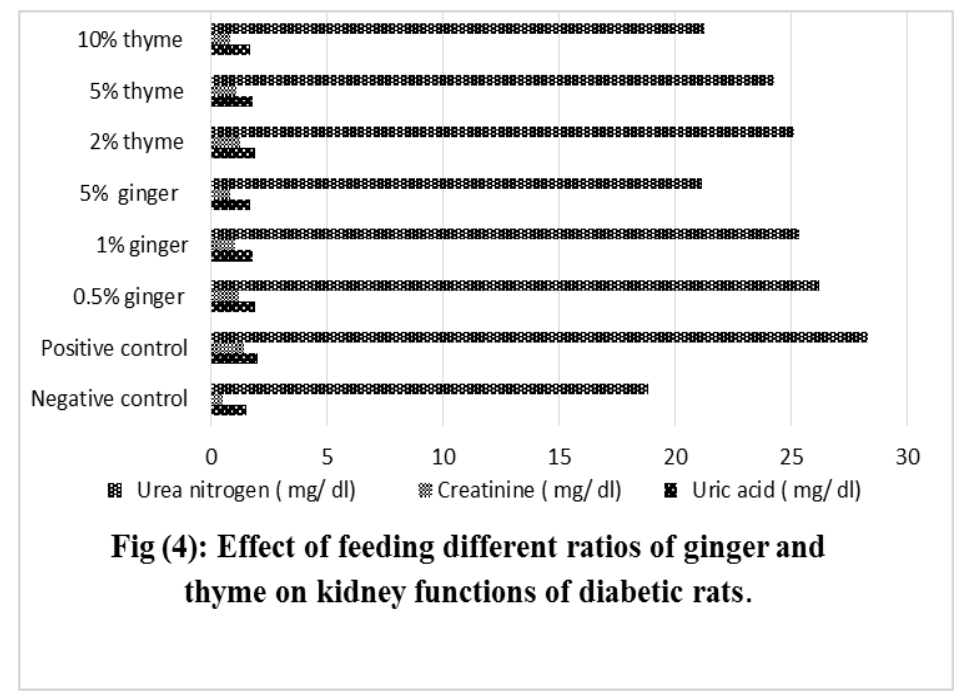

Results clarified in "Fig." (4) showed that plasma uric acid significantly increased in positive control, $(0.5 \%)$ ginger group and $2 \%$ thyme group as compared with negative control. However, there was significant decrease in (1\% and $5 \%)$ ginger groups and $10 \%$ thyme group as compared with positive control. [43] observed that, accelerated gluconeogensis and rates of protein degradation with negative nitrogen balance and muscle wasting occur in diabetic rats. Moreover, [44] found that, the correlation between glycaemic control and decline in renal function and a low urinary albumin excretion indicates that poor glycemic control can accelerate the loss of renal function in diabetic nephropathy. Creatinine level showed highly significant increase in positive control, $0.5 \%, 1 \%$ and $5 \%$ ginger, $2 \%, 5 \%$ and $10 \%$ thyme fed groups as compared with negative control. While it was significantly decreased in 5\% ginger and $10 \%$ thyme fed groups as compared with positive control. In addition, plasma urea was significantly increased in positive control, $0.5 \%$ and $1 \%$ ginger and $2 \%$ and $5 \%$ thyme fed groups as compared with negative control. It was significantly reduced in 5\% ginger and $2 \%, 5 \%$ and $10 \%$ thyme group as compared with positive control. These results were in agreement with that reported by [45, 46 and 10].

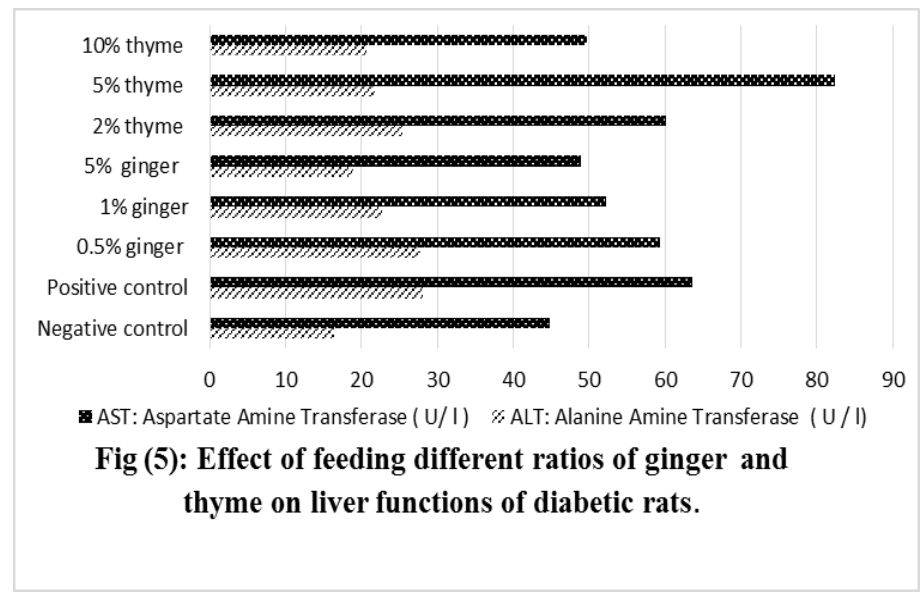

Results given in "Fig." (5) indicated that plasma ALT and AST was significantly increased for positive control, $0.5 \%$ and $1 \%$ ginger and $2 \%$ and $5 \%$ thyme groups as compared with negative control while showed significant reduction in $1 \%$ and 5\% ginger and 5\% and $10 \%$ thyme as compared with positive control. These results were in agreement with [47 and 48].

When comparing ginger (5\%) and thyme (10\%) there was statistically more significant improvement in $(5 \%)$ ginger than $(10 \%)$ thyme in serum glucose and HDL-C. 
Histopathological studies on liver:

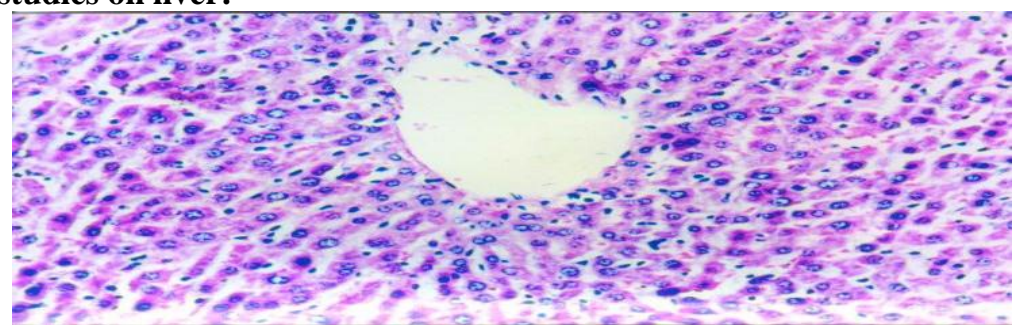

"Fig." (6) Liver of negative control rat showing the normal histological structure of hepatic lobule (Hand E X 200).

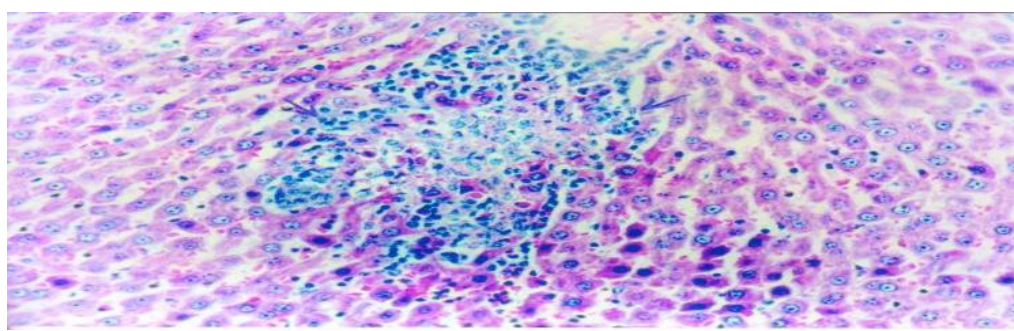

"Fig." (7) Liver of positive control rat showing focal area of hepatic necrosis completely replaced by leucocytic cells infiltration and focal hepatic hemorrhage (Hand E X 200).

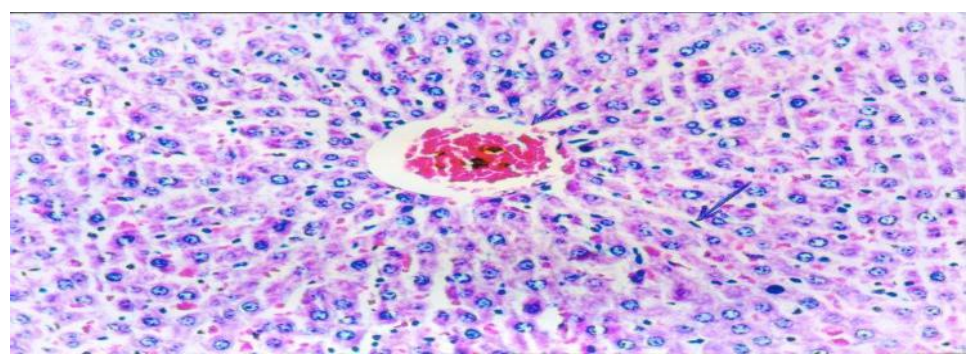

"Fig." (8) Liver of rat from (0.5\%) ginger group showing congestion of central vein and activation of kupffer cells and focal hepatic hemorrhage (Hand E X 200).

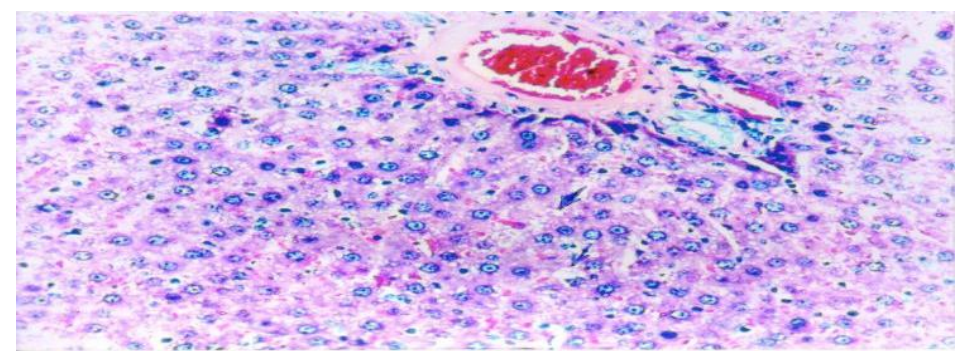

"Fig." (9) Liver of rat from (1\%) ginger group showing vacuolar degeneration of hepatocytes and focal area of hepatic necrosis completely replaced by leucocytic cells infiltration (Hand $\mathbf{E}$ X 200 ).

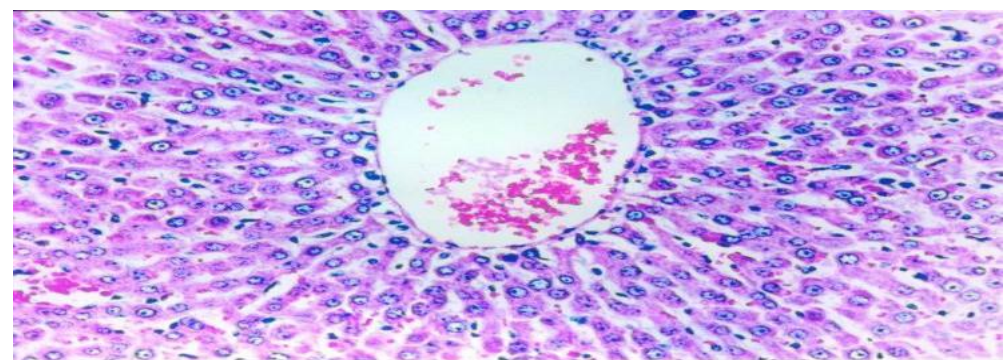

"Fig." (10) Liver of rat from (5\%) ginger group showing no histopathological changes (Hand E X 200). 


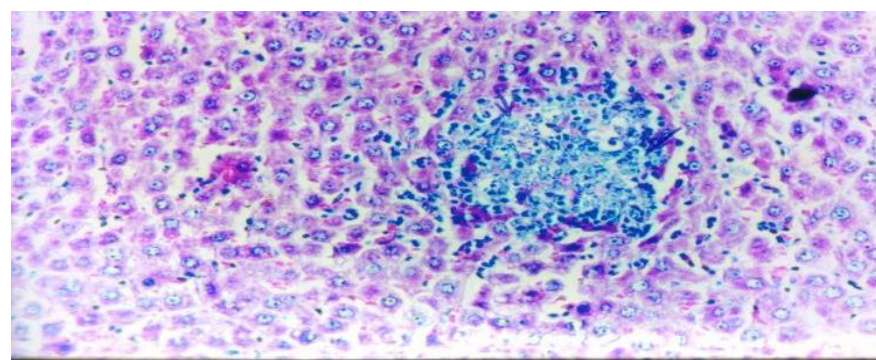

"Fig." (11) Liver of rat from (2\%) thyme group showing focal area of hepatic necrosis completely replaced by leucocytic cells infiltration. (Hand E X 200).

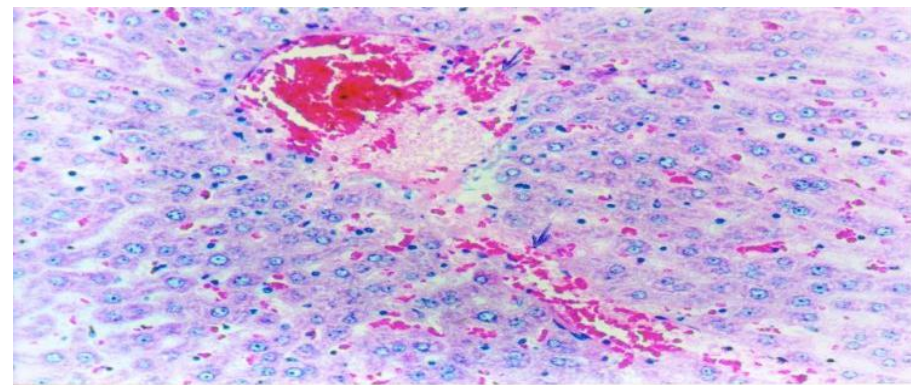

"Fig." (12) Liver of rat from (5\%) thyme group showing dilatation and congestion of central vein and hepatic sinusoids (Hand E X 200).

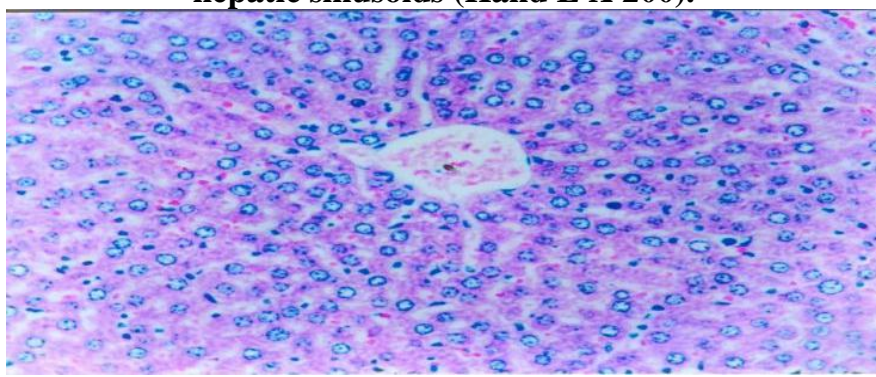

"Fig." (13) Liver of rat from (10\%) thyme group showing no histopathological changes (Hand E X 200).

These results were in agreement with, [49] who found that, raised ALT reflects fatty change in the liver and that this in turn reflects pathophysiological changes predating the development of type II diabetes. While, [50] showed that, treatment with $1 \%$ dietary ginger for 4 weeks in rats may have protective role against the vacuolar degeneration of hepatocytes and focal area of hepatic necrosis completely replaced by leucocytic cells infiltration.

\section{Conclusion}

According to the results of the present study, it was preferred to use 5\% ginger and 10\% thyme for their importance in diabetics in reduction of serum glucose and lipid profile levels, increase HDL-C and hemoglobin levels and improve liver and kidney functions. Diabetic patients could use ginger and thyme as spices on meat, beans, pizza etc or in other forms as fresh ginger, or decoction as tea.

\section{References}

[1] International Diabetes Federation IDF, Diabetes Atlas, 6th edition. 2013, Brussels.

[2] J.E. Shaw, R.A. Sicree, and P.Z. Zimmet, Global estimates of the prevalence of diabetes for 2010 and 2030, Diabetes Res Clin Pract. 87(1), 2010, 4-14.

[3] J. A. Ojewole, Analgesic, antiinflammatory and hypoglycaemic effects of ethanol extract of Zingiber officinale (Roscoe) rhizomes (Zingiberaceae) in mice and rats. Phytother Res., 20 (9), 2006, 764-72.

[4] R. S. Ahmed, V. Seth, and B. D. Banerjee, Influence of Dietary ginger (Zingiber officinalees Rosc) on Antioxidant defense system in rats: comparison with Ascorbic acid. Indian J.EXP Biol; 38 (6), 2000, $604-606$.

[5] G. El-Akabawy, W. El-Kholy, Neuroprotective effect of ginger in the brain of streptozotocin-induced diabetic rats. Ann Anat. Mar 12, 2014, S0940-9602 (14)00022-3.

[6] K.M. Soliman, and R.I. Badeaa, Effect of oil extracted from some medicinal plants on different mycotoxigenic fungi, Food and Chemical Toxicology, 40(11), 2002, 1669-1675.

[7] M. Hudaib, E. Speroni, A.M. Di Pietra, and V. Cavrini, GC/MS, evaluation of thyme (Thymus vulgaris L.) oil composition and variations during the vegetative cycle, Journal of Pharmaceutical and Biomedical Analysis, 29(4), 2002, 691-700.

[8] R. Aeschbach, J. Loliger, and B. C. Scott, Antioxidant actions of thymol, carvacol, 6-gingerol, zingerone and hydroxytyrosol, Food and Chemical Toxicology, 32(1), 1994, 31-36. 
[9] S. Fujisawa, and Y. Kadoma, Effect of phenolic compounds on the polymerization of methyl methacrylate, Dental Materials, 8(5), 1992, 324-326.

[10] H. Ozkol, Y. Tuluce, N. Dilsiz, and I. Koyuncu, Therapeutic potential of some plant extracts used in Turkish traditional medicine on streptozocin-induced type 1 diabetes mellitus in rats, J Membr Biol., 246(1), 2013, 47-55.

[11] D.M. Hegsted, R.C. Mills, C.A. Elvehyem, and E.B. Hart, Cholin in the nutrition of chicks, J. Biol. Chem., $138,1941,459$.

[12] J. A. Campbell, Methodology of protein evaluation, Beirut Fac. Agric. Sci. Publi., 21, 1963, 13.

[13] P.G. Reeves, F.H. Nielsen, G.C. Fahey, AIN-93 Purified Diets for Laboratory Rodents: Final Report of the American Institute of Nutrition Ad Hoc Writing Committee on the Reformulation of the AIN-76A Rodent Diet, J. Nutr. 123, 1993, $1939-1951$.

[14] V. Buko, O. Lukivskaya, V. Nikitin, Y. Tarasov, L. Zavodnik, A. Borodinsky, B. Gorenshtein, B. Janz, and K. J. Gundermann, Hepatic and pancreatic effects of polyenoylphosphatidyl choline in rats with alloxan induced diabetes. Cell Biochem. Funct., 14(2), 1996, 131-137.

[15] R. Kakkar, S.V. Mantha, J. Radhi, and K. Prasad, Increased oxidative stress in rat liver and pancreas during progression of streptozotocin-induced diabetes, Clinical Science 94, 1998, 623 - 32.

[16] National Diabetes Data Group, Classification and diagnosis of diabetes mellitus and other categories of glucose intolerance, Diabetes, 28 (12), 1979, 1039-1057.

[17] L. Drabkin, The standardization of hemoglobin measurement, Am .J.Med .Sci., 21, 1949, 710-715.

[18] N.D. Peterrs, The standardization of total protein Measurement, Am. J. Med. Sci., 23, 1968, 708.

[19] P. C. Fossati, and L. Prencipe, Triglycerides determination after enzymatic hydorolysis, Clin. Chem., $28,1982,2077$.

[20] C. C. Allain, L. S. Poon, S. G. Cicely, et al., Enzymatic Determination of Total Serum Cholesterol, Clin. Chem., 20, 1974, $470-475$.

[21] M. Burstein, H. R. Scholnick, and R. Morfin, Rapid method for the isolation of lipoproteins from human serum by precipitation with polyanions, J. Lipid res., 11(6), 1970, 583-595.

[22] W.T. Friedwald, R.I. Levy, and D.S. Fredrickson, Estimation of the concentration of low density lipoprotein cholesterol in plasma, without use of preparative ultracentrifuge, Clin. Chem., 18(6), 1972, 499-502.

[23] P. Fossati, L. Prencipe and G. Berti, Use of 3,5-dichloro-2-hydroxybenzenesulfonic acid/4-aminophenazone chromogenic system in direct enzymic assay of uric acid in serum and urine, Clin Chem. 26(2), 1980, 227-31.

[24] C.J. Patton, and S.R. Crouch, Enzymatic colorimetric method to determine urea in serum, Anal. Chem., 49, 1977, 464.

[25] S. Reitman, and S. Frankel, A colorimetric method for the determination of serum glutamic oxalacetic and glutamic pyruvic transaminases, Am. J. Clin. Pathol. 28(1), 1957, 56- 63.

[26] H. Bartels, and M. Bohmer, Creatinine standard and measurement of serum creatinine with picric acid, Clin. Chem. Acta ,32, 1971, 81-85.

[27] K. H. Abou- Hatab, and A. Sadek, Statistical Analysis system and research in psychological and social science, 1991, Elanglo, Egypt.

[28] E.M. Haroun, O.M. Mahmoud, and S.E. Adam, Effect of feeding cuminum cyminum fruits, Thymus Vulgaris leaves or their or mixture to rats, Vet. Hum. Toxicol., 44(2), 2002, 67-9.

[29] H.A. Mansour, A.A. Newairy, M.I. Yousef, and S.A. Sheweita, Biochemical study on the effects of some Egyptian herbs in alloxaninduced diabetic rats, Toxicology, 170 (3), 2002, 221-228.

[30] R.J. Verma, and V. Asnani, Ginger extract ameliorates paraben induced biochemical changes in liver and kidney of mice, Acta Pol. Pharm., 64, 2007, $217-220$.

[31] U. Bhandari, R. Kanojia and K. K. Pillai, Effect of ethanolic extract of Zingiber officinal on dyslipidaemia in diabetic rats, J. Ethnopharmacol., 28, 97(2), 2005, 227- 230.

[32] Z. M. Al-Amin, M. Thomson, K. K. Al- Qattan, R. Peltonen-Shalaby, and M. Ali, Anti- diabetic and hypolipidaemic properties of ginger in streptozotocin induced diabetic rats, Br. J. Nutr., 96(4), 2006, 660-6.

[33] R.K. Goyal, and S. V. Kadnur, Beneficial effects of Zingiber Officinale on goldthioglucose induced obesity, Fitoterapia, 77, 2006, $160-163$.

[34] B.O. Iranloye, A.P. Arikawe, G. Rotimi, and A.O. Sogbade, Anti-diabetic and anti-oxidant effects of Zingiber officinale on alloxaninduced and insulin-resistant diabetic male rats, Niger J. Physiol. Sci., 23, 26(1), 2011, 89-96.

[35] R. Alizadeh-Navaei, F. Roozbeh, M. Saravi, M. Pouramir, F. Jalali, and A. A. Moghadamnia, Investigation of the effect of ginger on the lipid levels. A double blind controlled clinical trial, Saudi Med. J., 29(9), 2008, 1280 - 4.

[36] H.R. Madkor, S.W. Mansour, and G.Ramadan, Modulatory effects of garlic, ginger, turmeric and their mixture on hyperglycaemia, dyslipidaemia and oxidative stress in streptozotocin -nicotinamide diabetic rats, Br. J. Nutr., 105(8), 2011, $1210-7$.

[37] A.S. Al-Noory, A.N. Amreen, and S. Hymoor, Antihyperlipidemic effects of ginger extracts in alloxan-induced diabetes and propylthiouracil-induced hypothyroidism in rats, Pharmacognosy Res., 5(3), 2013, 157-61.

[38] Z. W. Man, T. Hirashima, S. Mori, and K. Kawano, Decrease in triglycerides accumulation in tissue by restricted diet and improvement of diabetes in Otsuka Long-Evans Tokushima fatty rats, a non-insulin-dependent diabetes model, Metabolism, 49(1), $2000,108-14$.

[39] S. P. Akhani, S. L. Vishwakarma, and R. K. Goyal, Anti-diabetic activity of Zingiber officinale in streptozotocin - induced type 1 diabetic rats, J. Pharm. Pharmacol., 56(1), 2004, $101-5$.

[40] K. Sekiya, A. Ohtani, and S. Kusano, Enhancement of insulin sensitivity in adipocytes by ginger, Biofactors, 22 (1-4), 2004, 153156.

[41] P. Rosenblat, S. Nalini, and V. Menon, Effect of ginger on changes in morphology and cholesterol level in mice, Hamdard Medicus, 41(4), 2008, $56-59$.

[42] B. Fuhrman, M. Rosenblat, T. Hayek, R. Coleman, and M. Aviram, Ginger extract consumption reduces plasma cholesterol, inhibits LDL oxidation and attenuates development of atherosclerosis in atherosclerotic, apolipoprotein E-deficient mice, J. Nutr., 130(5), 2000, 1124-31.

[43] A.I. Vinik, and R.R. Wing, The good, the bad and the ugly in diabetic diets, Endocrinol. Metab. Clin. North Am., 21 (2), 1992 , 237 -279 .

[44] H. Mulec, G. Blohme, B. Grande, and S. Bjorck, The effect of metabolic control on rate of decline in renal function in insulin dependent diabetes mellitus with overt nephropathy, Nephrol. Fial. Transplant; 13, 1998, 651-5.

[45] H. Shirpoor, A.T. Afshari, A.F.R. Saadatia, and E. Saboory, The effect of ginger on diabetic nephropathy, plasma antioxidant capacity and lipid peroxidation in rats, Food Chemistry, 101, 2007, 148-153.

[46] K. Al-Qattan, M. Thomson, and M. Ali, Garlic (Allium sativum) and ginger (Zingiber officinale) attenuate structural nephropathy progression in streptozo- $\quad$ tocin-induced Diabetic rats, Biological Sciences, (21), 2007, 7-10. 
[47] M.C. Dias, A.L.T. Spinardi, M.A.M. Rodrigues, J.L.V. Camargo, E. Terna, Lack of chemopreventive effects of ginger on colon carcinogenesis induced by 1,2 - dimethylhydrazine in rats, Food and Chemical Toxicology, 44, 2006, $877-884$.

[48] I. Al-Saimary, S. Bakr, B. Khudaier, and Y. Abass, Efficiency of antibacterial agents extracted from Thymus vulgaris 1. (lamiaceae). The Internet Journal of Nutrition and Wellness, 4(1), 2006.

[49] B. Vozarova, C. Weyer, R. S. Lindsay, E. E. Pratley, C. Bogardus, and P. A. Tataranni, High white blood cell count is associated with a worsening of insulin sensitivity and predicts the development of type 2 diabetes, Diabetes, 51, 2002, $455-461$.

[50] K. P. Mallikarjuna, P. Sahitya Chetan, K. Sathyavelu Reddy, and W. Rajendra, Ethanol toxicity: Rehabilitation of hepatic antioxidant defense system with dietary ginger. Fitoterapia, 79(3), 2008, 174-8. 